\title{
The Skill Readiness for Energy Prosumer Behaviour at the Household Level
}

\author{
Adriana Grigorescu ${ }^{1, *}$ Cristina Lincaru ${ }^{2}$ \\ ${ }^{1}$ National University of Political Studies and Public Administration, Bucharest, Romania \\ ${ }^{2}$ National Scientific Research Institute for Labour and Social Protection - INCSMPS, Bucharest, Romania \\ *Corresponding author. Email: adriana.grigorescu@snspa.ro
}

\begin{abstract}
On the 2030 Agenda for Sustainable Development context, International Renewable Energy Agency (I.R.E.N.A., 2020) highlighted that renewable energy (RE) has proven more resilient than fossil fuels. Solar energy presents the highest potential, the individual consumer at the household level, could decide to become an energy producer if it will generate more than his self-consume. The new category of energy prosumers is a matter of investment in equipment and a skills issue. The study addressed a gap of evaluating the energy prosumer's skill readiness considering the digital transformation. Our original contribution is the proposed index of spatial patterns for prosumer skills readiness in Europe. These skills are for the new family business model of household's renewable energy production \& consume. Everybody will need skills to integrate new technologies, at various grades, according to SAMR model. At the same time, the natural potential and the technology are components of fast shift to RE. Prosumer skill readiness is a complimentary picture for the high digital skills requested by Industry 4.0. Through self-consuming, its members (usually family) create new value and profit outside the market. Results of the present research offers an integrated view of hard resources (natural, technological) and soft/intellectual resources (skill, knowledge) meant to contribute to the RE. It provides valuable insights for the other public policies considering the economic crisis (austerity), energy crisis, diminishing risks and increasing resilience.
\end{abstract}

Keywords: Skill, Prosumer, Renewable Energy Production, Resilience.

\section{INTRODUCTION}

The actual challenge that are facing by the European countries, but not only is the energy crises. In is not less true that, at the global level there are consistent concerns about the energy consumption and the environmental effects. One of the acting directions to implement a sustainable development is the decarbonization. This target could be achieved by shifting the energy production and consume to renewable energy (RE) as solar, wind and geothermal energy. Concurrent to this, the high price of the classic energy will impact the consumers, especially the individuals, without minimising the effect on the small and medium enterprises (SMEs). That is why a send concurrent direction has to be addressed: the inclusive and resilient society.

The 2030 agenda comes with a significant package of solutions to be implemented covering economic, environmental and social dimensions. In accordance with the actual trends the RE has a great potential to substitute the fossil energy: its share was double in 2019 compared with 2004; the faster growing energy source is the solar and there are behavioural changings reflected in one of fifth heating or cooling source and about $10 \%$ in transport activities [1].

Even so, the change of the consumer behavior is not supported at European Union (EU) level by the RE production. EU imports of solar panels, biodiesel and wind turbines in 2020 exceed exports, and knows a significant growth compared with 2015, since the exports declined except of biodiesel.

In terms of socio-economic impact, among the RE sources the highest potential of jobs creation (about $75 \%$ ) belongs to solar energy, followed by the wind (about 24\%) [2]. 
Ntanos et.al. shows a stronger correlation between the consumption from renewable energy sources (RES) in the countries with a higher GDP than the one with a lower GDP, at least for 25 European countries studied [3]. From other perspectives Tahri et.al. founded climate as the most important factor in defining the photovoltaic energy production [4].

In the last years there were developed several studies about the resources, potential, advantages and disadvantage and the impact [5] [6] [7] [8] [9] driving to the conclusion that the solar energy is one of the component with high potential that support the shift to sustainable, decarbonised economies and resilient inclusive societies.

The identified gap in the literature is about the skills readiness of the solar energy consumer and producers and their capability to become prosumers. In our opinion, besides the resources and natural potential, the skills and the agility to accept the new role and business concepts are very important. Solar energy seems to be a solution for the shift to clean energy at the household level. It is well known that the household contribution to the pollution is very high, since they are using fossil energy.

The research question is: Do the European contries have the skill readiness for energy prosumer behaviour at the household level?

The explored hypotheses are:

Hypothesis 1 (H1) - Skill readiness for energy prosumer behaviour differs from country to country in $E U$ ?

Hypothesis $2(\mathrm{H} 2)$ - there is spatial synchronicity between photovoltaic $(P V)$ power potential and skill readiness.

\section{CONCEPTUALIZATION AND LITERATURE REVIEW}

\subsection{Digital transformation and solar energy}

The ICT development creates the $4^{\text {th }}$ wave called the Industry 4.0 Revolution, the main factor that determines radical innovation in all socio-economic areas and with impact on environment. Desruelle et.al. [10] considered that digital transformation (DT) is a profound process of changing all the human life aspects by using, integrating and applying the digital technologies and products.

J-P De Clerck founded the i-SCOOP in Brussels
(Belgium) over two decades ago, now a digital business and transformation hub [11]. The industry 4.0 is defined by i-SCOOP [11] as the informationintensive transformation of manufacturing connected with big data, people, processes, services, systems and Internet od Things (IoT) that are using the data and information to generate smart industries and ecosystems, characterised by innovation and collaboration [11].

DT opens unexpected opportunities for a new economy, and for energy sector at multi-scale level:

a. A new relationship among producer and consumer that affect the entire value chain. Industry 4.0 need full value chain perspectives, including suppliers, origins of the materials, other smart manufacturing components, the end-to-end digital supply chain and the final destination - the end user/consumer [11];

b. New concept of mobility of people and goods [10];

c. Disruptive changes in construction sector in terms of technical solutions, value chain, sustainability, environment protection [10];

d. The new role and use of data and information in building smart industries and ecosystems [11];

e. A new structure of the energy sector, especially in RE Sources utilisation in order to keep the energy supply secure, affordable, stable, and sustainable [10] and diversification though innovation i.e., creating new energy services and products;

f. New options for Government and Public Administration to increase interaction with the citizens and to offer better services [10].

\subsection{SAMR model and learning though technology}

For the intensive transformation though new role and use of data, the highest priority is the capability to learn, to use and to exploit radical new disruptive technologies. DT is a double-edged sword: increases the opportunities or increases the gap and the community is left behind.

The difference is given by the ability to learn to use the "right" technology appropriate with the local potential, in our case the local solar energy potential.1 
A powerful model, in literature, to learn through technology is SAMR model that are proposing the evolution chain starting with Substitution, Augmentation, Modification and ending with Redefinition. SAMR launched by Puentedura (2006), develop digital learning experiences that are using technology in highly creative manner. [12], [13].

The SAMR model in the DT context is synthetized by Fastiggi [14], and the two stages enhancement and transformation are completed with automating and informating.

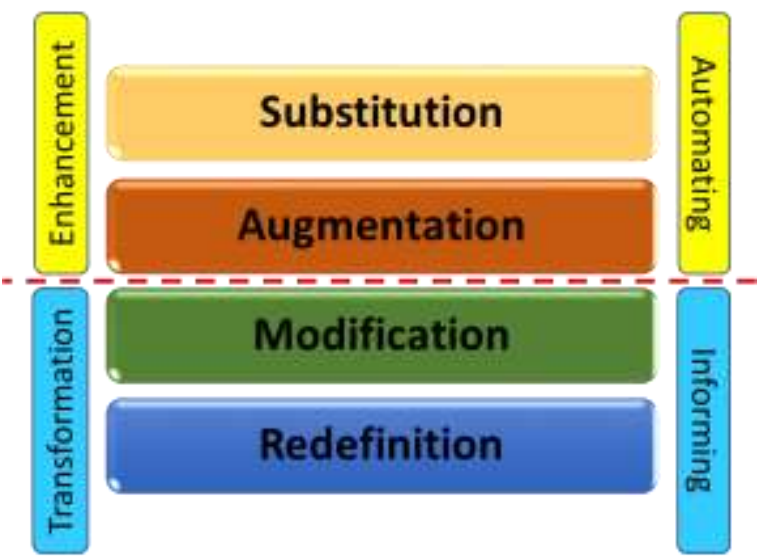

Figure 1. SAMR model and digital transformation Source: Authors adaptation of Puentedura [12] and Fastiggi [14]

According to Puentedura [12] and Fastiggi [14] there are two main stages (Figure 1):

a) Enhancement/Automating happens in the first two steps: Substitution \& Augmentation levels represent an enhancement of existing ways of working. The technology simply provides the updated tools and environment for learning to take place. This stage is considered more technical update

b) Transformation/Information happens in the next two steps: Modification and Redefinition levels are the creative one and they represent transformational stages. The DT is actively helping to transform the way in which learning can occur. Especially those two steps are more connected with knowledge economy, producing innovation and new knowledge.

Shortly, the new model of learning and creating new is reflecting the omnipresence manifestation of DT. It reflects the weaving of "learn to use technology and use technology to learn".

\subsection{Prosumer typologies}

The classic economy explains the roles of producers and consumers in a linear sequentially manner. Knowledge economy brings in action DT and on this radical new framework, the roles of producers and consumers has been changed, they could act in a simultaneously manner. This is the prosumer concept, which "reflects the double behaviour of producer and consumer", launched since 1980 by Toffler. The author, in its famous book The Third Wave, announced in a visionary manner, that the consumers will contribute to the design of the product they want to buy and consume. Therefore they become an integrated part of the development process of the producer, shifting from consumers to prosumers [15].

Vikram [16] identify in 2006, tree types of new actors on the market considering the knowledge and information exploitation:

a. Producer \& Consumer - contributing to the production and consume it as well (the most known examples: Q\&A forums, Wikipedia and social media);

b. Product and brand advocate - the consumer are more active and present using the social media and other digital facilities, they are easier highlighted the "plusses" and the "minuses" of a product. Reviewers and bloggers are consuming and commenting on the products and develop a new business;

c. Semi-Professional Consumer - it was increased the information content about professional products and some of them are included in complex products. The best examples are the professional cameras used successfully by bloggers, tourists, and hobbyists and the mobile phone cameras that are reaching high performance.

Vikram [16] is proposing a matrix of prosumer type and economic sector exemplifying new business models in media \& advertising, healthcare, consumer goods, education, travel, food industry, fitness \& wellness. 


\subsection{Energy Prosumer}

We exemplify the need for skills readiness for the energy prosumer, defined as "a consumer of energy who also produces energy to provide for their needs, and who in the instance of their production exceeding their requirements, will sell, store or trade the surplus energy". [17]

Another working definition of the prosumer is referring to smart grid: "Smart grid customers may both consume and produce energy (so-called prosumers), and may directly contribute to control and optimize the global system"[18]

Prosumerism is gaining share in the new business and is playing at the global level. It is straightforward and cost-effective for households, for individuals and groups [17]. As an energy prosumer, it will generate energy and consume and share it with others regardless of the form. It will determine groups of prosumers with energetic independence.

Changing the energy use means changing the energy culture. Ford et. al. defines the energy culture as the "household's combination of material objects, practices and norms" [17]. From the perspective of energy use, Ford et al. define the Active prosumers against Passive prosumers. The decision process makes the difference [17]. He also synthetize a five steps process in initiating an energy prosumer project:

Step 1 - Aspiration for energy generation;

Step 2 - Research, learning, planning;

Step 3 - Funding;

Step 4 - Installation, set-up, project launch;

Step 5 - Generating and on-going management.

The difference between the active and passive prosumers rises in step 1 . The reasons for developing the aspiration are pro-active for the first one, it comes from the desire to access new technology to improve the eco-system, sine the passive decided to access this solution mainly due to external constrictions or part of other project.

The second step is one of the most important; it is related to the consumer's knowledge and skill and the aspiration of becoming a prosumer. Depending on the type (active or passive), this step is approached differently (Figure 2). An active prosumer will look for information about new technologies, the best process and infrastructure, capabilities and advantages. The passive prosumer will look to the simplest solution, easy to be used and cost-efective. That is why we considered that the skills readiness is a key factor for shifting the household level to the prosumerist behaviour.
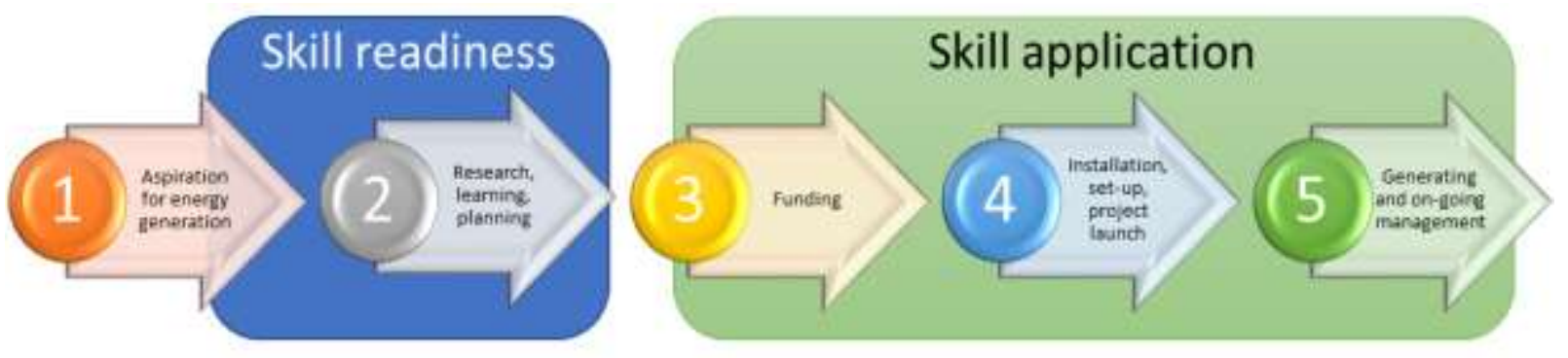

Figure 2. Skill readiness and the steps undertaken to initiate prosumer energy projects

Source: authors adaptation based on Ford et el [11]

\section{DATA AND INDICATORS}

We design the Prosumer Skills Readiness Index (PSRI) complementary to the ESMAP /WB methodology [19]. Our contribution is given by the digital transformation new opportunities and challenges to use solar energy by a prosumer \& communities of prosumers.

Considering the behavior of the active prosumers, the digital technologies amplify the photovoltaic potential in the places where prosumers act. The second contribution comes from the synchronicity of the PV potential and the index of skills readiness.

Starting from the Figure 2 for the flow to initiate the energy projects, we considered the steps in the logic of digital transformation. Between production and consumption stages intervenes the technology and the ability to use technology to learn, expressed by the SAMR model. 
In Table 1 we formalise the 3 measures iterated above production, consumption and the smart use of technology. The smart use of technology radically changes the consumption culture and the production practices as corresponding dimensions. The SAMR measure for technology use and learning comprehensive technology includes five dimensions: norms, market, funding, technology \& skills and collective / cooperation. The DT is derived by The Top 10 Social Media Sites \& Platforms, evaluated to be in 2021: Facebook, Twitter, LinkedIn, Instagram, Snapchat, TikTok, Pinterest, Reddit, YouTube, and WhatsApp [20]

Table 1. Input measures, dimensions and variables and indicators used PSRI calculation

\begin{tabular}{|c|c|c|c|}
\hline Measure & Dimension & Variable name & Eurostat Indicator \\
\hline Production & Practices & SolarPr & $\begin{array}{l}\text { Electricity production capacities for renewables and } \\
\text { wastes [NRG_INF_EPCRW_custom_1694887] }\end{array}$ \\
\hline \multirow[t]{2}{*}{ Consumption } & Undesirable (high) & Hcons & $\begin{array}{l}\text { Final energy consumption in households per capita } \\
\text { [SDG_07_20] }\end{array}$ \\
\hline & Desirable (high) & psolch & $\begin{array}{l}\text { Final energy consumption in households by type of fuel } \\
\text { [TEN00125_custom_1696037] - Share of solar in total }\end{array}$ \\
\hline \multirow[t]{5}{*}{ SAMR } & Norms & DigAut & $\begin{array}{l}\text { Individuals using the internet for interaction with public } \\
\text { authorities [TIN00012] }\end{array}$ \\
\hline & Market & DigSell & $\begin{array}{l}\text { Individuals using the internet for selling goods or } \\
\text { services [TIN00098] }\end{array}$ \\
\hline & Funding & DigBank & $\begin{array}{l}\text { Individuals using the internet for internet banking } \\
\text { [TIN00099] }\end{array}$ \\
\hline & Technology \& Skills & DigLearn & $\begin{array}{l}\text { Individuals using the internet for doing an online course } \\
\text { [TIN00103] }\end{array}$ \\
\hline & Collective / Cooperation & DigNetw & $\begin{array}{l}\text { Individuals using the internet for participating in social } \\
\text { networks [TIN00127] }\end{array}$ \\
\hline
\end{tabular}

Source: Authors concept, Values are detailed in Annex Table 3

Solar energy is everywhere globally, but there is a long way to use it through market or auto consumption. There is also a rich literature regarding the photovoltaic potential measurement tools and to evaluate the potential solar energy and the use.

SolarGIS calculate the global data representing the solar resource and PV power output in every country of the world [19]. These data are available through Global Solar Atlas web-based tool commissioned and funded by the Energy Sector Management Assistance Program (ESMAP). The map allow to "make high-level comparisons between countries and regions on their theoretical, practical, and economic solar potential" [19]

The SolarGIS methodology (ESMAP/WB methodology) includes tree types of data: primary data layers, secondary data layers and supplementary data, from rich data sources [19]. We are shortly present below the data used to generate the SolarGIS map following the information provided by the producer \{19]

Primary data layers includes [19]:

a) From the Solargis source: Global horizontal irradiance, air temperature at 2 meters, PV power production potential (PVOUT), seasonal variability derived from monthly PVOUT values.

b) From I.R.E.NA. SOURCE: the cost of electricity (LCOE - the levelized cost of energy) derived from PVOUT and economic data, administrative boundaries (country borders), PV installed capacity.

Secondary Data layers includes: Terrain elevation and slope, Built-up areas, Population clusters, Tree cover density, Land cover, Water bodies and Protected areas [19].

Supplementary data from The World Bank: Population, Area, GDP per capita, Human Development Index, Electric power consumption, Access to electricity, Reliability of supply and transparency of tariff, Approximate electricity tariffs [19].

\section{MATH AND EQUATIONS}

Exploitation of the solar energy through market or through auto-consumption, at the household level involves many factors and implies a complex decision chain. The active prosumer behaviour includes steps: strategy, smart data management, 
entrepreneurship (funding, technology, production), marketing and market if is the case and consumption. Different tools are used to measure this behaviour:

Respondents' perception on their usage of RES and on their contribution to life quality is done for Attica Urban Area in Greece [18] with the tools of Principal Components Analysis and Logit Regression. Lee and Chen [21] use Multi-Criteria Decision Making (MCDM) to solve energy selection problems because these problems involve. Authors rank the RES as follows: solar PV as the best choice from social perspective, wind energy as the best choice from environmental perspective and hydropower from the economic cost perspective (with the most mature technology).

The demand for project decision input for solar farming develops a lot of literature that uses geographic information system (GIS) tools and the MCDM method. Sánchez-Lozano et.al created an analysis tool combining GIS \& MCDM [22] for evaluation of solar farm locations in the South Eastern Spain. Analytical Hierarchy Process (AHP) to calculate the corresponding criteria weights. With the same tools, the recent Global Photovoltaic Power Potential by Country [19].

Siksnelyte-Butkiene et. al. [23] reviews in 2020 the scientific literature that have used multiplecriteria decision-making (MCDM) methods as a key tool to evaluate renewable energy technologies in households. Authors emphasise that the household sector consumes almost one third of all energy produced. To answer the question of how to choose the right renewable energy production technologies in households, decision relevant of active prosumer behaviour, Siksnelyte-Butkiene et. al realized a multidimensional evaluation (economic, social, environmental, and technological) with MCDM methods but without digital transformation criteria.

The area of China's agricultural \& solar roof power generation projects is studied by Wu et.al [24] into two categories: urban housing roof PV power generation and rural life with electricity photovoltaic power generation. Authors used Multiple Attribute Decision making Problem (MADM) with 10 criteria and 23 sub-criteria, but none of it related to digital transformation.

We use the Decision-Making Tools at Work steps from the Multi-Criterial Decision Analyse (MCDA) Methods according to Baker et.al. [25] and apply the following 4 steps methodology:

\section{M.1. Selecting the best value}

*Each criterion has different values

*Criteria analysis - scale representation for qualitative values

\section{M.2. Building the Decision Matrix}

$\mathrm{X}_{\mathrm{ij}}=$ performance value for alternative $i$ to criterion $j$

Beneficial criteria the desirable values are the high values

Non-beneficial criteria the undesirable values are small values

\section{M.3. Normalization of criteria's}

Beneficial criteria $=\quad \mathrm{X}_{\mathrm{ij}} / \operatorname{Max}\left(\mathrm{X}_{\mathrm{ij}}\right)$ (1)

Non-beneficial criteria $=\operatorname{Min}\left(\mathrm{X}_{\mathrm{ij}}\right) / \mathrm{X}_{\mathrm{ij}}$ (2)

\section{M.4. Building the standard performance decision} matrix and PSRI

$\left[\mathrm{C}_{\mathrm{ij}}\right]$ is an aggregate index for PSR with 3 criteria: Production, Consumption and SAMPR is presented in table 1 calculated as follows:

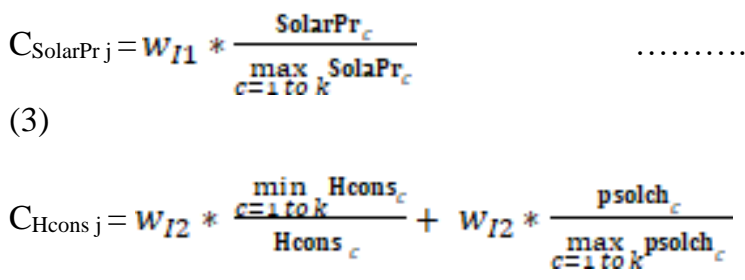

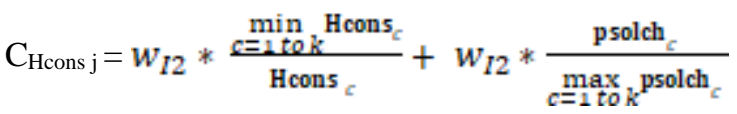

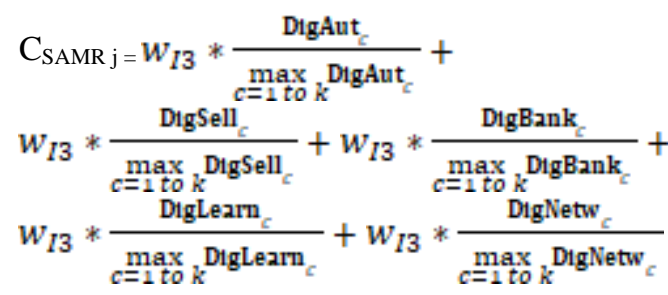

Where: $\mathrm{i}$ is the variable, $\mathrm{j}$ the country, from 1 to $\mathrm{k}$ the total number of analyzed countries, w equal weights by aggregation round (I and II)

$$
\mathrm{C}_{\mathrm{Pr}}=\mathrm{C}_{\text {SolarPr }}{ }^{*} \mathrm{~W}_{\mathrm{II}}+\mathrm{C}_{\mathrm{Hcons}}{ }^{*} \mathrm{~W}_{\mathrm{II}}+\mathrm{I}_{\mathrm{SAMR}}{ }^{*} \mathrm{~W}_{\mathrm{II}}
$$

Assignment of weights - Equal weights - all criteria are equally important number of criteria

$$
\mathrm{W}_{\mathrm{j}}=1 / \mathrm{n} * 100,
$$


The PSRI is represented in a choropleth map using the Jenks natural breaks classification method in Arc Gis 10.2.2 software. We use this method to visualize the Index in a optimized manner, knowing that "this is method seeks to reduce the variance within classes and maximize the variance between classes" [26]

Even if the theoretical maximum of the PSRI is one, the maximum real level is 0.44 in 2019 for Malta. This fact indicates that the analyzed European countries work under potential.

The limit of our methodology is given by its Analytic of Hierarchy Process (AHP) simple approach for the alternatives and criteria, which are scored using "equal importance or preference" weighting scale.

\section{RESULTS}

Our main result is the map in the Figure 3 of the spatial distribution of Prosumer Readiness Skills Index for 2019 in European countries. (Annex: Table 3, 4, and 5). With the exception of Turkey for the European area studied the spatial pattern is increasing from East to Westside of the Europe. The PSRI indicates a major gap for the Central and Eastern European Countries (CEE) with low index values below 0.23 and countries like Spain, the UK, and the 0.30 index. A notable exception is Italy that is having the same behavior as the CEE countries. The best performers are Northern countries (Finland, Denmark, Iceland, United Kingdom and Netherland) and from South the Spain and Portugal.

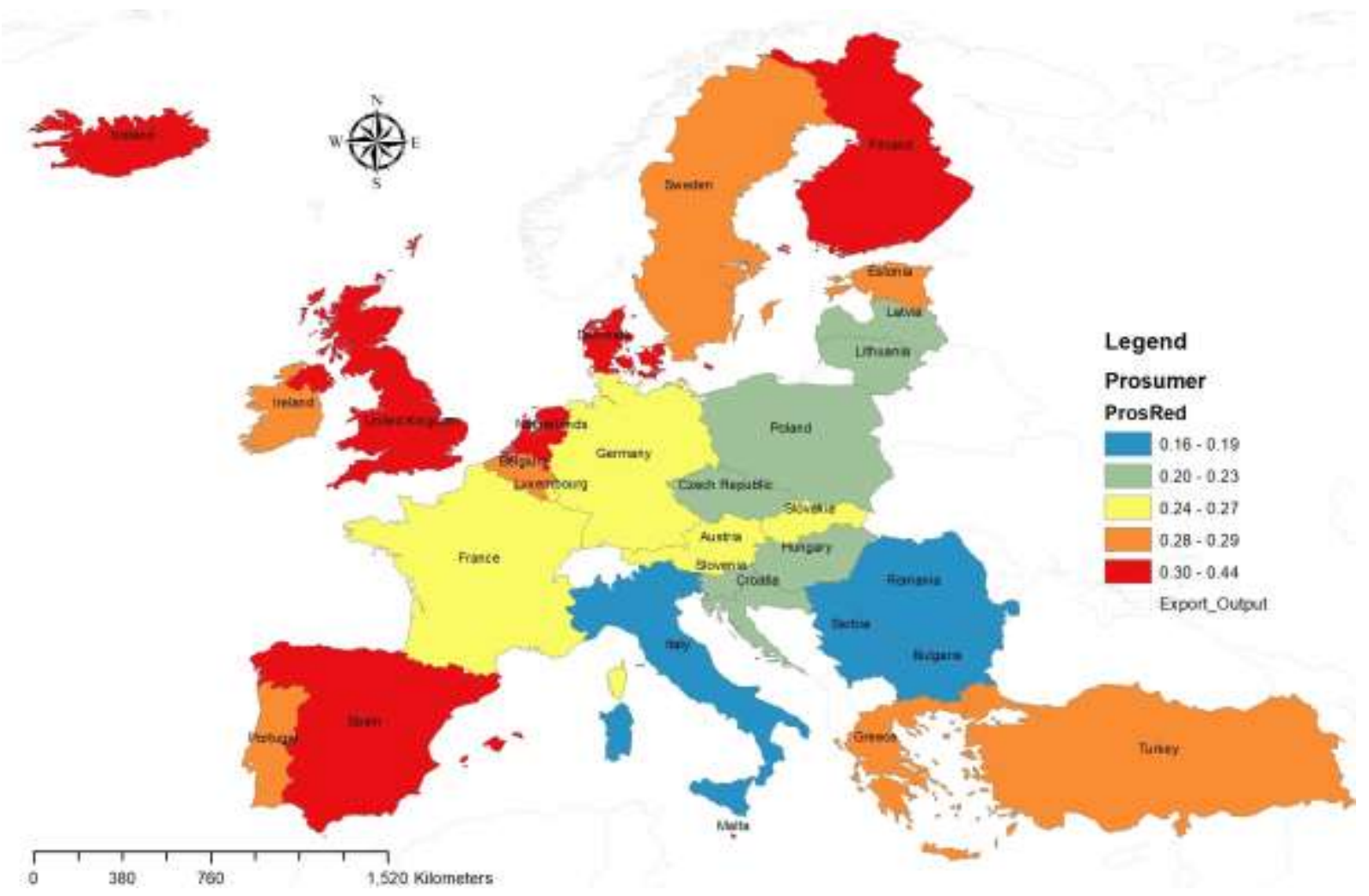

Figure 3. Prosumer Skill Readiness Index for 2019 in European countries

Source: Author PSRI model results 


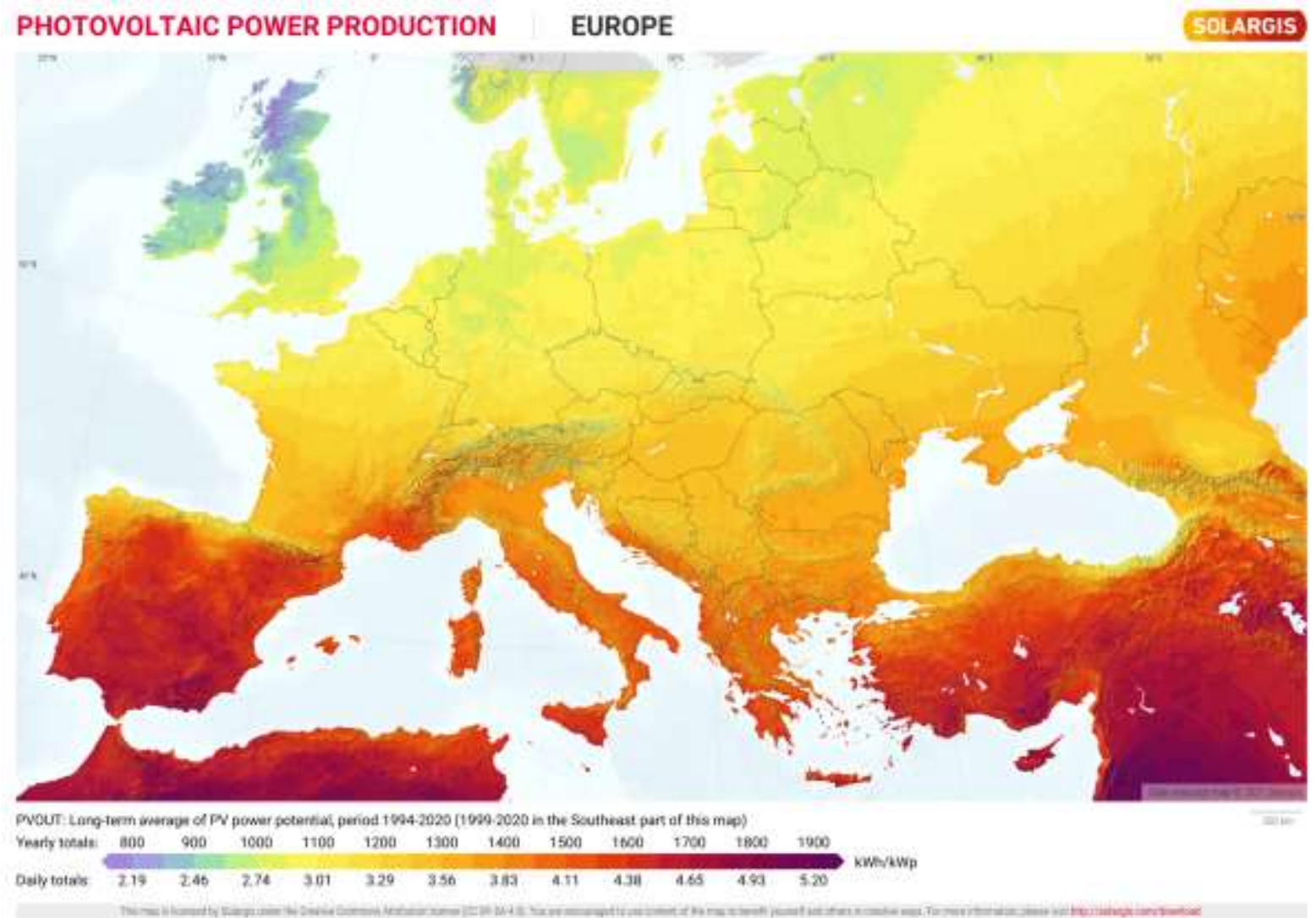

Figure 4. PV power production potential in European countries Global Solar Atlas 2.0

Source: Map extract from SolarGIS https://solargis.com/

The next step of our research is to extract the map using the data from the Global Solar Atlas 2.0, a free, web-based application developed and operated by the company Solargis s.r.o. on behalf of the World Bank Group, with funding provided by the Energy Sector Management Assistance Program (ESMAP). The generated map reflects the PV potential power for the European countries.

In Figure 4 is visible that European countries score at the lower end of the ranking, with an average PVOUT below $3.5 \mathrm{kWh} / \mathrm{kWp}$, except those in southern Europe with values below $5 \mathrm{kWh} / \mathrm{kWp}$. The best performer with a global ranking from 209 countries are Cyprus ( 51 rank, 4.7 PVOUT, Malta
(68 rank, 4.56 PVOUT), Spain (68 rank, 4.41 PVOUT), Turkey(96 rank, 4.32 PVOUT), Portugal(99 rank, 4.32 PVOUT), Greece(120 rank, 4.14 PVOUT), Italy(139 rank, 3.99 PVOUT), Bulgaria(164 rank, 3.7 PVOUT), Croatia(171 rank, 3.63 PVOUT), Romania(177 rank, 3.52 PVOUT) and Serbia(178 rank, 3.52 PVOUT).

The final step of our research was to superpose the two maps for the European countries, offering a complex picture of the energy presumes potential. 


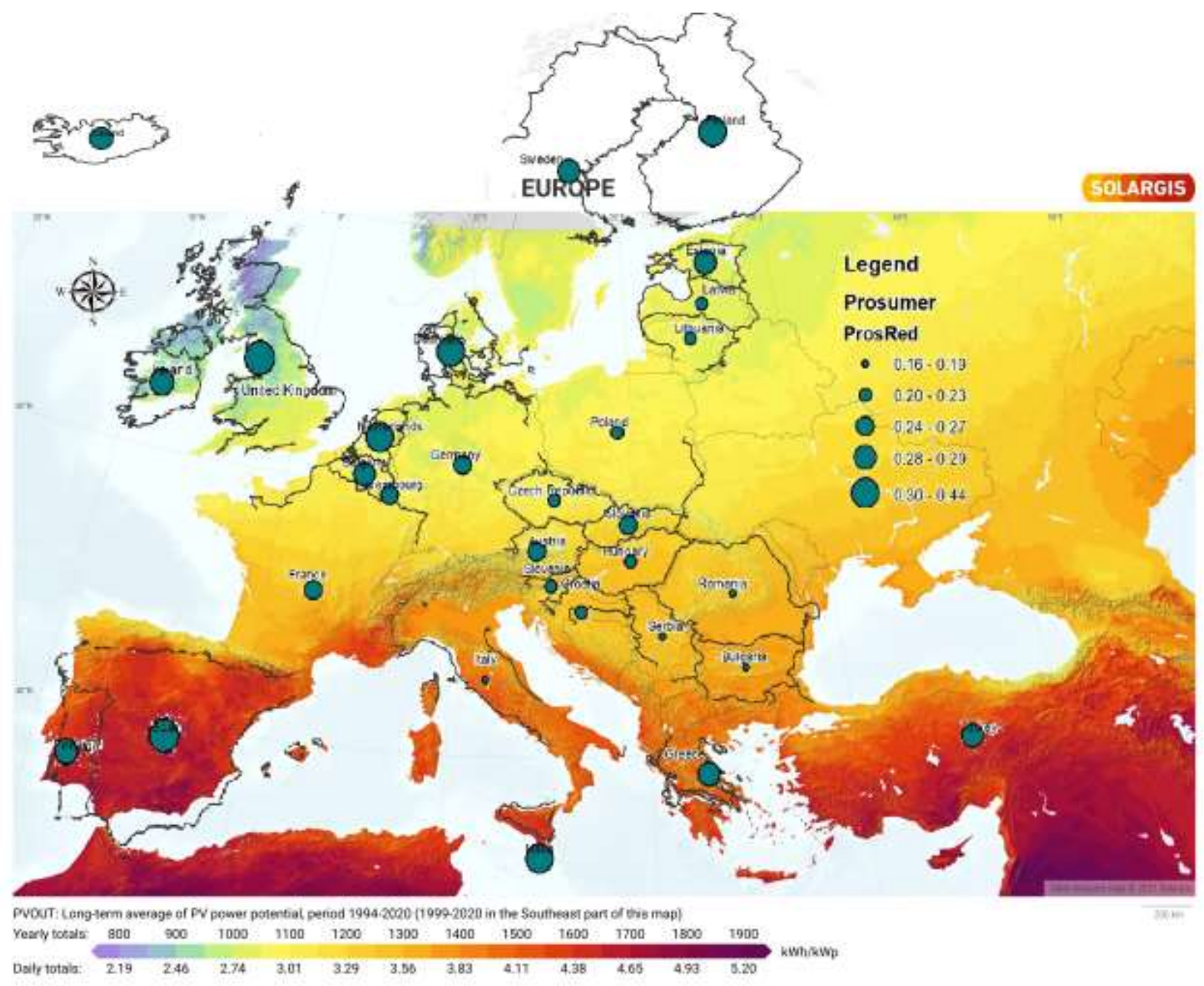

Figure 4. Superpose of PSRI for 2019 and PV Production maps

Source: Authors construction

\section{DISCUSSIONS AND CONCLUSION}

As it could be seen in Figure 4, the Solargis "Photovoltaic power output of a PV system, the longterm power output produced by a utility-scale installation of monofacial modules fixed mounted at an optimum tilt, measured in $\mathrm{kWh} / \mathrm{kWp} /$ day" is low for European countries, with few exeption.

This map result after we overlay the calculated PSRI for 2019 in European countries on the Solargis map.

The raster map of Solargis is superposed over the shapefile of Index map following Mc Harg [27] and DiBiase and Dutton [28]. It looks that PSRI is higher in the North of Europe (Finland, United Kingdom, Denmark and Iceland), where is long time culture of managing energy than in areas with higher PV power potential. Spain, Tukey and Portugal present relative high potential of both PSRI and higher PV power potential.

Looking at the PSRI as a measure of capability of a community (country) to fully exploit the opportunities of digital transformation then, the ranking of PV power potential could be changed. These results could provide valuable insights for the new integrated economic, social and environment energy public policy development.

Based on the obtained results we can appreciate that $\mathrm{H} 1$ was confirmed, since the $\mathrm{H} 2$ wasn't.

Hypothesis 1 (H1) - Skills readiness for energy prosumer behaviour differs from country to country in EU? The PSRI shows that the European countries record values from 0.16 to 0.44 , covering 5 levels of readiness. These are influencing the appearance and growth of the active prosumers. 
Hypothesis 2 (H2) - there is special synchronicity between photovoltaic $(P V)$ power potential and skills readiness. The map superposed confirmed that there is no synchronicity between the natural resources and human resources. This is generating different behaviour and evolution in the shifting process to the RE.

A further development of this conclusions will be subject of deeper analyse and proposed methodology of public policies design.

Active prosumers are the new actors in the new digital transformed energy sector era and the digital transformation offers new opportunities to use solar energy, if prosumers have the right skills.

Prosumer is not only a producer and a consumer, it includes the SAMR dimensions as a measure o knowledge and innovation society, on the digital transformation background:

Table 2.

\begin{tabular}{|c|c|}
\hline Measure & Dimension (detail) \\
\hline \multirow{5}{*}{$\begin{array}{l}\text { SAMR } \\
\text { Digital learning }\end{array}$} & Norms \\
\hline & Market \\
\hline & Funding \\
\hline & Technology \& Skills \\
\hline & Collectives / Cooperation \\
\hline
\end{tabular}

Prosumer has to manage intensive digital information processes: strategy, smart data management, entrepreneurship (funding, technology, production), marketing and market if is the case and consumption, not fully yet covered by literature. Each chain link involves complex decision that involve multiple and often conflicting criteria.

PV power potential is enhanced if there is an energy culture for prosumers communities building, as it is the Northern European countries case. An extensive perspective could be offered by combining the actual results and PSRI \& PV potential with the country profiles for synergy of knowledge transfer within the sustainable development [29].

\section{AUTHORS' CONTRIBUTIONS}

The authors contributions raised in developing an index to evaluate the skill reediness in European countries, considering the digital transformation components.

At the same time the superposed map of PSRI on the SolarGIS map of PV power potential offers an integrated perspective of the European countries capabilities to faster implement the clean energy policies and to shift to the new business model in energy sectr.

\section{ACKNOWLEDGMENTS}

This work support by a grant from the Romanian Ministry of Research and Innovation, Programme NUCLEU, 2019-2022, project no: Functional perspectives of the local labour markets in Romania, in the context of the smart and innovative economy, code PN 19_13_01_01.

\section{REFERENCES}

[1] Eurostat, 'Green energy products 2020: EU imports exceed exports', ec.europa.eu, Feb. 12, 2021.

https://ec.europa.eu/eurostat/web/products-

eurostat-news/product/-

/asset_publisher/VWJkHuaYvLIN/content/id/13

726435/pop_up (accessed September. 17, 2021).

[2] I.R.E.N.A., 'Global Renewables Outlook: Energy Transformation 2050', International Renewable Energy Agency, Abu Dhabi, 2020. [Online]. Available: www.irena.org/publications

[3] Ntanos S, Skordoulis M, Kyriakopoulos G, Arabatzis G, Chalikias M, Galatsidas S, Batzios A, Katsarou A. (2018) Renewable Energy and Economic Growth: Evidence from European Countries. Sustainability. 2018; 10(8):2626. https://doi.org/10.3390/su10082626

[4] M. Tahri, M. Hakdaoui, and M. Maanan, 'The evaluation of solar farm locations applying Geographic Information System and MultiCriteria Decision-Making methods: Case study in southern Morocco', Renewable and Sustainable Energy Reviews, vol. 51, pp. 13541362, Nov. 2015, doi: 10.1016/j.rser.2015.07.054.

[5] Guangul, F. M., \& Chala, G. T. (2019, January). Solar energy as renewable energy source: SWOT analysis. In 2019 4th MEC international conference on big data and smart city (ICBDSC) (pp. 1-5). IEEE.

[6] Boamah, F. (2020). Desirable or debatable? Putting Africa's decentralised solar energy futures in context. Energy Research \& Social Science, 62, 101390.

[7] Al-Shahri, O. A., Ismail, F. B., Hannan, M. A., Lipu, M. H., Al-Shetwi, A. Q., Begum, R. A., ... \& Soujeri, E. (2021). Solar photovoltaic energy 
optimization methods, challenges and issues: A comprehensive review. Journal of Cleaner Production, 284, 125465.

[8] Nguyen, V. H., \& Wu, J. C. (2018). Recent developments in the design of photoreactors for solar energy conversion from water splitting and $\mathrm{CO} 2$ reduction. Applied Catalysis A: General, 550, 122-141.

[9] Hosseini, S. E., \& Wahid, M. A. (2020). Hydrogen from solar energy, a clean energy carrier from a sustainable source of energy. International Journal of Energy Research, 44(6), 4110-4131.

[10] Desruelle P. (Ed.), Baldini G., Barboni M., Bono F., Delipetrev B., Duch Brown N., Fernandez Macias E., Gkoumas K., Joossens E., Kalpaka A., Nepelski D., Nunes de Lima M. V., Pagano A., Prettico G., Sanchez I., Sobolewski M., Triaille J.-P., Tsakalidis A., Urzi Brancati M. C., Digital Transformation in Transport, Construction, Energy, Government and Public Administration, EUR 29782 EN, Publications Office of the European Union, Luxembourg, 2019, ISBN 978-92-76-08613-0, doi:10.2760/689200, JRC116179. Available: https://ec.europa.eu/jrc/communities/sites/defaul t/files/jrc_digital_transformation_final_on_line_ en_baja_resolucion_online.pdf

[11] i-SCOOP, 'Industry 4.0 and the fourth industrial revolution explained', i-SCOOP, 2021. https://www.i-scoop.eu/industry-4-0/ (accessed September 18, 2021).

[12] Puentedura, R.R. (2014) Learning, Technology, and the SAMR Model: Goals, Processes, and Practice, available at http://www.hippasus.com/rrpweblog/archives/20 14/06/29/LearningTechnologySAMRModel.pdf

[13] Sckrock, K., 'SAMR and Bloomțs', Kathy Schrock's Guide to Everything. https://www.schrockguide.net/samr.html (accessed September 17, 2021)

[14] Fastiggi, W. (2014) 'The SAMR Model', Technology for Learners. Learn to use technology and use technology to learn, 2014. https://technologyforlearners.com/the-samrmodel/ (accessed Aug. 02, 2020).

[15] Toffler, A. (1980) The Third Wave. Morrow, 1980, translation in Romanian language 1983, Ed. Politica, Bucharest, Romania
[16] Vikram, A. (2016) 'The rise of PROsumers (And what it means for CONsumer companies)', Medium, Sep. $\quad 10, \quad 2016$. https://medium.com/@aditya.vikram/the-rise-ofprosumers-and-what-it-means-for-consumercompanies-26d408325934 (accessed September 02, 2021).

[17] Ford, R., Stephenson, J., \& Whitaker, J. (2016). Prosumer Collectives: a review. Dunedin, NZ: University of Otago, New Zealand, May 2016. [Online]. Available: https://www.mbie.govt.nz/assets/27e4fc3a4f/pro sumer-collectives-a-review-2016.pdf

[18] Espe, E., Potdar, V, Chang, E. (2018) 'Prosumer Communities and Relationships in Smart Grids: A Literature Review, Evolution and Future Directions', Energies, vol. 11, no. 10, p. 2528, Sep. 2018, doi: 10.3390/en11102528.

[19] ESMAP, 'Global Photovoltaic Power Potential by Country', World Bank, Washington, DC, Jun. 2020. [Online]. Available: https://documents1.worldbank.org/curated/en/46 6331592817725242/pdf/Global-PhotovoltaicPower-Potential-by-Country.pdf

[20] Walsh, S. (2021) 'The Top 10 Social Media Sites \& Platforms 2021', Search Engine Journal. https://www.searchenginejournal.com/socialmedia/biggest-social-media-sites/ (accessed September 21, 2021).

[21] Lee, H.-C., Chang, C.-T. (2018) 'Comparative analysis of MCDM methods for ranking renewable energy sources in Taiwan', Renewable and Sustainable Energy Reviews, vol. 92, pp. 883-896, Sep. 2018, doi: 10.1016/j.rser.2018.05.007.

[22] Sánchez-Lozano, J. M., Teruel-Solano, J., SotoElvira, P.L., Socorro García-Cascales, M., (2013) 'Geographical Information Systems (GIS) and Multi-Criteria Decision Making (MCDM) methods for the evaluation of solar farms locations: Case study in south-eastern Spain', Renewable and Sustainable Energy Reviews, vol. 24, pp. 544-556, Aug. 2013, doi: 10.1016/j.rser.2013.03.019.

[23] I. Siksnelyte-Butkiene, E. K. Zavadskas, and D. Streimikiene, 'Multi-Criteria Decision-Making (MCDM) for the Assessment of Renewable Energy Technologies in a Household: A Review', Energies, vol. 13, no. 5, p. 1164, Mar. 2020, doi: 10.3390/en13051164. 
[24] Wu, Y., Wang, Z. (2017) 'The Decision-making of Agriculture \& Solar Complementary Roof Power Generation Project in Rural Area', Energy Procedia, vol. 105, pp. 3663-3672, May 2017, doi: 10.1016/j.egypro.2017.03.843.

[25] Baker, Dennis \& Bridges, Donald \& Hunter, Regina \& Johnson, Gregory \& Krupa, Joseph \& Murphy, James \& Sorenson, Ken. (2001). Guidebook to Decision-Making Methods. USA Department of Energy, vol. WSRC-IM-200200002, 2001, Accessed: May 15, 2020. [Online]. Available:

https://www.researchgate.net/publication/25562 1095_Guidebook_to_Decision-

Making_Methods

[26] Jenks, G. F. (1967) 'The Data Model Concept in Statistical Mapping', in International Yearbook of Cartography, Volume 7, 1967, pp. 186-190.
[27] McHarg, I. L. (2018) Design with Nature. 1971. Accessed: May 01, 2018. [Online]. Available: https://books.google.ro/books?id=CovnoQEAC AAJ

[28] DiBiase, D., Dutton, J.A. (2009) '5. Map Overlay Concept | The Nature of Geographic Information', PennState College of earth and Mineral Sciences, Department of Geography, 2009. https://www.eeducation.psu.edu/natureofgeoinfo/c9_p6.html (accessed Oct. 27, 2019).

[29] Grigorescu, A.; Ion, A.-E.; Lincaru, C.; Pirciog, S. Synergy Analysis of Knowledge Transfer for the Energy Sector within the Framework of Sustainable Development of the European Countries. Energies 2022, 15, 276. https://doi.org/10.3390/en15010276

\section{ANNEX}

Table 3. Decision Matris $\left(\mathrm{X}_{\mathrm{ij}}\right)$

\begin{tabular}{|c|c|c|c|c|c|c|c|c|}
\hline Varia & SolarPr & Hcons & psolch & DigAut & DigSell & DigBank & DigLearn & DigNetw \\
\hline [u.m.] & [Megawatt] & \begin{tabular}{|l|}
{$[$ Kilogram } \\
of oil \\
equivalent \\
$($ KGOE)]
\end{tabular} & $\begin{array}{l}\text { [Thousand } \\
\text { tons of oil } \\
\text { equivalent] }\end{array}$ & {$\left[\begin{array}{l}{[\text { Percentage }} \\
\text { of } \\
\text { individuals] }\end{array}\right.$} & $\begin{array}{l}\text { [Percentage } \\
\text { of } \\
\text { individuals] }\end{array}$ & {$\left[\begin{array}{l}\text { [Percentage } \\
\text { of } \\
\text { individuals }]\end{array}\right]$} & $\begin{array}{l}\text { [Percentage } \\
\text { of } \\
\text { individuals] }\end{array}$ & {$\left[\begin{array}{r}\text { [Percentage } \\
\text { of individuals] }\end{array}\right.$} \\
\hline Austria & 1702 & 750 & 1.7 & 70.0 & 12.0 & 63.0 & 8.0 & 56.0 \\
\hline Belgium & 4637 & 688 & 0.3 & 59.0 & 24.0 & 71.0 & 9.0 & 76.0 \\
\hline Bulgaria & 1048 & 310 & 0.5 & 25.0 & 6.0 & 9.0 & 2.0 & 53.0 \\
\hline Croatia & 85 & 550 & 0.5 & 33.0 & 22.0 & 46.0 & 5.0 & 58.0 \\
\hline Cyprus & 151 & 411 & 17.1 & 50.0 & 3.0 & 41.0 & 6.0 & 72.0 \\
\hline $\begin{array}{l}\text { Czech } \\
\text { Republic }\end{array}$ & 2086 & 657 & 0.2 & 54.0 & 12.0 & 68.0 & 6.0 & 59.0 \\
\hline Denmark & 1080 & 752 & 0.3 & 92.0 & 28.0 & 91.0 & 12.0 & 81.0 \\
\hline Estonia & 121 & 717 & 0.0 & 80.0 & 18.0 & 81.0 & 14.0 & 65.0 \\
\hline Finland & 222 & 1,020 & 0.0 & 87.0 & 32.0 & 91.0 & 21.0 & 67.0 \\
\hline France & 10795 & 593 & 0.4 & 75.0 & 22.0 & 66.0 & 8.0 & 42.0 \\
\hline Germany & 49047 & 695 & 1.2 & 59.0 & 30.0 & 61.0 & 8.0 & 53.0 \\
\hline Greece & 2834 & 384 & 6.7 & 52.0 & 2.0 & 31.0 & 6.0 & 57.0 \\
\hline Hungary & 1400 & 581 & 0.2 & 53.0 & 13.0 & 47.0 & 6.0 & 69.0 \\
\hline Iceland & 0 & 1,259 & 0.0 & 89.0 & 21.0 & 94.0 & 20.0 & 92.0 \\
\hline Ireland & 31 & 584 & 0.5 & 61.0 & 19.0 & 67.0 & 13.0 & 64.0 \\
\hline Italy & 20865 & 521 & 0.5 & 23.0 & 8.0 & 36.0 & 7.0 & 42.0 \\
\hline Latvia & 3 & 621 & 0.0 & 70.0 & 9.0 & 72.0 & 4.0 & 65.0 \\
\hline Lithuania & 103 & 518 & 0.0 & 55.0 & 9.0 & 65.0 & 7.0 & 61.0 \\
\hline Luxembour & 160 & 744 & 0.5 & 60.0 & 16.0 & 71.0 & 10.0 & 63.0 \\
\hline Malta & 154 & 201 & 5.0 & 50.0 & 30.0 & 54.0 & 12.0 & 71.0 \\
\hline Netherlands & 7177 & 537 & 0.2 & 81.0 & 36.0 & 91.0 & 13.0 & 67.0 \\
\hline Poland & 1539 & 479 & 0.4 & 40.0 & 14.0 & 47.0 & 5.0 & 53.0 \\
\hline Portugal & 901 & 281 & 2.0 & 41.0 & 9.0 & 42.0 & 6.0 & 60.0 \\
\hline
\end{tabular}




\begin{tabular}{|l|l|l|l|l|l|l|l|l|l|}
\hline Romania & 1398 & 400 & 0.0 & 12.0 & 3.0 & 8.0 & 3.0 & 60.0 \\
\hline Serbia & 11 & 411 & 0.0 & 29.0 & 12.0 & 18.0 & 5.0 & 55.0 \\
\hline Slovakia & 590 & 485 & 0.3 & 59.0 & 22.0 & 55.0 & 5.0 & 59.0 \\
\hline Slovenia & 264 & 506 & 1.0 & 53.0 & 18.0 & 47.0 & 5.0 & 52.0 \\
\hline Spain & 11277 & 313 & 1.9 & 58.0 & 14.0 & 55.0 & 15.0 & 59.0 \\
\hline Sweden & 714 & 716 & 0.1 & 86.0 & & 84.0 & 18.0 & 72.0 \\
\hline Turkey & 5995 & 261 & 2.5 & 51.0 & 16.0 & 35.0 & 2.0 & 60.0 \\
\hline United & 13346 & 571 & 0.1 & 63.0 & 31.0 & 78.0 & 19.0 & 73.0 \\
Kingdom & & & & & & & & \\
\hline max & 49047 & $1,259$. & 17.1 & 92.0 & 36.0 & 94.0 & 21.0 & 92.0 \\
\hline min & 0 & 201. & 0.0 & 12.0 & 2.0 & 8.0 & 2.0 & 42.0 \\
\hline
\end{tabular}

Source: Authors data for variables named in Table 1

Table 4. Normalised decision matrix (NXij)

\begin{tabular}{|c|c|c|c|c|c|c|c|c|}
\hline Country & SolarPr & Hcons & psolch & DigAut & DigSell & DigBank & DigLearn & DigNetw \\
\hline Malta & 0.00 & 1.00 & 0.29 & 0.54 & 0.83 & 0.57 & 0.57 & 0.77 \\
\hline Cyprus & 0.00 & 0.49 & 1.00 & 0.54 & 0.08 & 0.44 & 0.29 & 0.78 \\
\hline Netherlands & 0.15 & 0.37 & 0.01 & 0.88 & 1.00 & 0.97 & 0.62 & 0.73 \\
\hline Finland & 0.00 & 0.20 & 0.00 & 0.95 & 0.89 & 0.97 & 1.00 & 0.73 \\
\hline United Kingdom & 0.27 & 0.35 & 0.01 & 0.68 & 0.86 & 0.83 & 0.90 & 0.79 \\
\hline Denmark & 0.02 & 0.27 & 0.02 & 1.00 & 0.78 & 0.97 & 0.57 & 0.88 \\
\hline Iceland & 0.00 & 0.16 & 0.00 & 0.97 & 0.58 & 1.00 & 0.95 & 1.00 \\
\hline Spain & 0.23 & 0.64 & 0.11 & 0.63 & 0.39 & 0.59 & 0.71 & 0.64 \\
\hline Turkey & 0.12 & 0.77 & 0.15 & 0.55 & 0.44 & 0.37 & 0.10 & 0.65 \\
\hline Estonia & 0.00 & 0.28 & 0.00 & 0.87 & 0.50 & 0.86 & 0.67 & 0.71 \\
\hline Sweden & 0.01 & 0.28 & 0.01 & 0.93 & 0.00 & 0.89 & 0.86 & 0.78 \\
\hline Portugal & 0.02 & 0.72 & 0.12 & 0.45 & 0.25 & 0.45 & 0.29 & 0.65 \\
\hline Ireland & 0.00 & 0.34 & 0.03 & 0.66 & 0.53 & 0.71 & 0.62 & 0.70 \\
\hline Greece & 0.06 & 0.52 & 0.39 & 0.57 & 0.06 & 0.33 & 0.29 & 0.62 \\
\hline Belgium & 0.09 & 0.29 & 0.02 & 0.64 & 0.67 & 0.76 & 0.43 & 0.83 \\
\hline Germany & 1.00 & 0.29 & 0.07 & 0.64 & 0.83 & 0.65 & 0.38 & 0.58 \\
\hline France & 0.22 & 0.34 & 0.03 & 0.82 & 0.61 & 0.70 & 0.38 & 0.46 \\
\hline Slovakia & 0.01 & 0.41 & 0.02 & 0.64 & 0.61 & 0.59 & 0.24 & 0.64 \\
\hline Luxembourg & 0.00 & 0.27 & 0.03 & 0.65 & 0.44 & 0.76 & 0.48 & 0.68 \\
\hline Austria & 0.03 & 0.27 & 0.10 & 0.76 & 0.33 & 0.67 & 0.38 & 0.61 \\
\hline Slovenia & 0.01 & 0.40 & 0.06 & 0.58 & 0.50 & 0.50 & 0.24 & 0.57 \\
\hline Lithuania & 0.00 & 0.39 & 0.00 & 0.60 & 0.25 & 0.69 & 0.33 & 0.66 \\
\hline Latvia & 0.00 & 0.32 & 0.00 & 0.76 & 0.25 & 0.77 & 0.19 & 0.71 \\
\hline Hungary & 0.03 & 0.35 & 0.01 & 0.58 & 0.36 & 0.50 & 0.29 & 0.75 \\
\hline Czech Republic & 0.04 & 0.31 & 0.01 & 0.59 & 0.33 & 0.72 & 0.29 & 0.64 \\
\hline Croatia & 0.00 & 0.37 & 0.03 & 0.36 & 0.61 & 0.49 & 0.24 & 0.63 \\
\hline Poland & 0.03 & 0.42 & 0.02 & 0.43 & 0.39 & 0.50 & 0.24 & 0.58 \\
\hline Bulgaria & 0.02 & 0.65 & 0.03 & 0.27 & 0.17 & 0.10 & 0.10 & 0.58 \\
\hline Serbia & 0.00 & 0.49 & 0.00 & 0.32 & 0.33 & 0.19 & 0.24 & 0.60 \\
\hline Italy & 0.43 & 0.39 & 0.03 & 0.25 & 0.22 & 0.38 & 0.33 & 0.46 \\
\hline Romania & 0.03 & 0.50 & 0.00 & 0.13 & 0.08 & 0.09 & 0.14 & 0.65 \\
\hline
\end{tabular}

Source: Data calculated by authors 
Table 5. The standard performance decision matrix and the PSRI

\begin{tabular}{|c|c|c|c|c|}
\hline \multirow[t]{2}{*}{ Country } & \multicolumn{3}{|c|}{$\mathrm{Cij}$} & \multirow{2}{*}{$\begin{array}{l}\text { Prosumer Skills Rediness } \\
\text { Index }\end{array}$} \\
\hline & SolarPr & Hcons & SAMR & \\
\hline Malta & 0.00 & 0.65 & 0.66 & 0.44 \\
\hline Cyprus & 0.00 & 0.74 & 0.43 & 0.39 \\
\hline Netherlands & 0.15 & 0.19 & 0.84 & 0.34 \\
\hline Finland & 0.00 & 0.10 & 0.91 & 0.34 \\
\hline United Kingdom & 0.27 & 0.18 & 0.81 & 0.33 \\
\hline Denmark & 0.02 & 0.14 & 0.84 & 0.33 \\
\hline Iceland & 0.00 & 0.08 & 0.90 & 0.33 \\
\hline Spain & 0.23 & 0.38 & 0.59 & 0.32 \\
\hline Turkey & 0.12 & 0.46 & 0.42 & 0.29 \\
\hline Estonia & 0.00 & 0.14 & 0.72 & 0.29 \\
\hline Sweden & 0.01 & 0.14 & 0.69 & 0.28 \\
\hline Portugal & 0.02 & 0.42 & 0.42 & 0.28 \\
\hline Ireland & 0.00 & 0.19 & 0.64 & 0.28 \\
\hline Greece & 0.06 & 0.46 & 0.37 & 0.28 \\
\hline Belgium & 0.09 & 0.16 & 0.66 & 0.27 \\
\hline Germany & 1.00 & 0.18 & 0.62 & 0.27 \\
\hline France & 0.22 & 0.18 & 0.59 & 0.26 \\
\hline Slovakia & 0.01 & 0.21 & 0.54 & 0.25 \\
\hline Luxembourg & 0.00 & 0.15 & 0.60 & 0.25 \\
\hline Austria & 0.03 & 0.18 & 0.55 & 0.24 \\
\hline Slovenia & 0.01 & 0.23 & 0.48 & 0.23 \\
\hline Lithuania & 0.00 & 0.19 & 0.51 & 0.23 \\
\hline Latvia & 0.00 & 0.16 & 0.53 & 0.23 \\
\hline Hungary & 0.03 & 0.18 & 0.49 & 0.22 \\
\hline Czech Republic & 0.04 & 0.16 & 0.51 & 0.22 \\
\hline Croatia & 0.00 & 0.20 & 0.47 & 0.22 \\
\hline Poland & 0.03 & 0.22 & 0.43 & 0.22 \\
\hline Bulgaria & 0.02 & 0.34 & 0.24 & 0.19 \\
\hline Serbia & 0.00 & 0.24 & 0.34 & 0.19 \\
\hline Italy & 0.43 & 0.21 & 0.33 & 0.18 \\
\hline Romania & 0.03 & 0.25 & 0.22 & 0.16 \\
\hline
\end{tabular}

Source: Results calculated by authors 